Check for updates

Cite this: Mater. Adv., 2020, 1,2433

Received 20th July 2020, Accepted 2nd September 2020

DOI: 10.1039/d0ma00524j

rsc.li/materials-advances

\title{
Tuning the morphology of manganese oxide nanostructures for obtaining both high gravimetric and volumetric capacitance $\dagger$
}

\author{
Jones de A. Pereira, ${ }^{a}$ Janiny N. Lacerda, ${ }^{a}$ Izabella F. Coelho, ${ }^{a}$ \\ Cauê de S. C. Nogueira, ${ }^{b}$ Dante F. Franceschini, ${ }^{a}$ Eduardo A. Ponzio, \\ Fernando B. Mainier ${ }^{a}$ and Yutao Xing (D) *b
}

\begin{abstract}
Obtaining both high gravimetric capacitance $\left(C_{s_{-} m}\right)$ and high volumetric capacitance $\left(C_{s_{-}} v\right)$ in supercapacitors is still a great challenge. We prepared manganese oxide ( $\mathrm{MO}$ ) nanostructures by pulsed laser deposition, using a metallic $\mathrm{Mn}$ target in an $\mathrm{O}_{2}$ atmosphere with pressures ranging from 0.1 Torr to 2.0 Torr at room temperature. The morphology gradually changed from a dense film to nanofoam with different porosities and densities. Raman spectroscopy and X-ray photoelectron spectroscopy revealed a similar oxidation state despite distinct microstructures. $C_{s_{-} m}$ and $C_{s_{-} v}$ for the three typical nanostructures, namely thin films, perpendicular columnar structures and nanofoams, were compared. It was found that the highest $C_{s_{\_} m}$ value was not obtained in the nanofoam sample with the highest porosity, but it was achieved in the sample with a perpendicular columnar structure with a $C_{s_{\_} m}$ value of $976 \mathrm{~F} \mathrm{~g}^{-1}$ at $5 \mathrm{mV} \mathrm{s}^{-1}$. Such a configuration showed the highest $C_{s_{-} v}$ as well with a value of $830 \mathrm{~F} \mathrm{~cm}^{-3}$ at $5 \mathrm{mV} \mathrm{s}^{-1}$. The best performance with voltage scan rates higher than $50 \mathrm{mV} \mathrm{s}^{-1}$ was found in the nanofoam structures with the values of $612 \mathrm{~F} \mathrm{~g}^{-1}$ at $100 \mathrm{mV} \mathrm{s}^{-1}$ and $352 \mathrm{~F} \mathrm{~g}^{-1}$ at $300 \mathrm{mV} \mathrm{s}^{-1}$. Our research gives useful suggestions for material design in supercapacitor electrodes: a suitable microstructure can be used for applications focusing on different parameters of a supercapacitor. The results might be of general interest for the energy storage research community.
\end{abstract}

\section{Introduction}

Supercapacitors are promising energy storage devices with desirable properties such as long life-time, high power density and faster charge/discharge rate, which fill well the gap between conventional capacitors and batteries. ${ }^{1-3}$ The most commonly used electrode materials are active carbon materials $^{4,5}$ (graphenes, ${ }^{6}$ nanotubes, ${ }^{7}$ and carbon materials obtained from biomass ${ }^{8}$ ), conducting polymers, ${ }^{9}$ metallic nanoparticles, ${ }^{10}$ transition metal oxides and selenides, ${ }^{11-13}$

\footnotetext{
${ }^{a}$ Departamento de Engenharia Quimica e de Petróleo, Universidade Federal Fluminense, 24210-346, Niterói, RJ, Brazil

${ }^{b}$ Laboratório de Microscopia Eletrônica de Alta Resolução, Centro de Caracterização Avançada para Indústria de Petróleo (LaMAR/CAIPE), Universidade Federal Fluminense, 24210-346, Niterói, RJ, Brazil. E-mail: xy@id.uff.br

${ }^{c}$ Grupo de Eletroquímica e Eletroanalitica (G2E), Instituto de Química,

Universidade Federal Fluminense, Campus Valonguinho, 24020-141,

Niterói, RJ, Brazil

$\dagger$ Electronic supplementary information (ESI) available: Deposition conditions and other parameters for the MO nanostructures, XPS survey spectra and fitting results of the $\mathrm{O}$ spectra, cyclic voltammetry and cycling stability profile of other samples and calculations of capacitive contribution. See DOI: 10.1039/ d0ma00524j
}

and composite materials. ${ }^{14-17}$ Manganese oxides (MOs) have been widely studied as electrode materials, due to their high energy storage capacity, abundancy in nature and low cost. ${ }^{18-20}$ MOs can exist in several oxidation states $\left(\mathrm{Mn}^{2+}, \mathrm{Mn}^{3+}\right.$ and $\mathrm{Mn}^{4+}$ ), forming different oxides, such as $\mathrm{MnO}, \mathrm{Mn}_{3} \mathrm{O}_{4}, \mathrm{Mn}_{2} \mathrm{O}_{3}$ and $\mathrm{MnO}_{2} \cdot{ }^{21,22}$ The most commonly used MO for supercapacitors is $\mathrm{MnO}_{2},{ }^{20,23}$ but other oxides like $\mathrm{Mn}_{3} \mathrm{O}_{4}$ have been more and more investigated. ${ }^{24}$ The gravimetric capacitance $\left(C_{\mathrm{s} \_\mathrm{m}}\right)$ obtained for the pure $\mathrm{Mn}_{3} \mathrm{O}_{4}$ phase ${ }^{25}$ is $401 \mathrm{~F} \mathrm{~g}^{-1}$ at $10 \mathrm{mV} \mathrm{s}^{-1}$ and for the $\mathrm{Mn}_{2} \mathrm{O}_{3}$ crystalline phase, the value is $460 \mathrm{~F} \mathrm{~g}^{-1}$ at $10 \mathrm{mV} \mathrm{s}^{-1} \cdot{ }^{26}$

Despite many advantages, MOs do not undergo fast ion diffusion in the bulk form, and thus the pseudo-capacitance is mainly provided by surface reactions. ${ }^{27}$ Therefore, the performance of MOs as supercapacitor electrodes is dominated by a specific surface area ${ }^{27}$ and for this reason, nanostructured MOs are usually used as supercapacitor electrodes. Nanostructured electrodes can be prepared by different methods, for example, chemical and electrochemical methods, ${ }^{18,28}$ electrophoretic deposition, ${ }^{29}$ physical vapor deposition ${ }^{30}$ sol-gel methods, ${ }^{31,32}$ hydrothermal methods ${ }^{33}$ and successive ionic layer adsorption and reaction methods. ${ }^{34,35}$ Pulsed laser 
deposition (PLD) in the presence of a buffer gas has been reported as a versatile tool for fabricating nanoparticles and other nanostructures with controlled size. ${ }^{36-38}$ This technique is used to synthesize MO electrodes as well. ${ }^{39-42}$ Yang synthesized MOs using manganese metallic and $\mathrm{Mn}_{3} \mathrm{O}_{4}$ targets in an $\mathrm{O}_{2}$ atmosphere with pressures ranging from 1 mTorr to 0.5 Torr and obtained crystalline phases of $\mathrm{Mn}_{2} \mathrm{O}_{3}, \mathrm{Mn}_{3} \mathrm{O}_{4}$ and amorphous $\mathrm{MnO}_{x}{ }^{43}$ With the background gas pressures being higher than those used for the production of nanoparticles, a new type of nanostructure, namely nanofoam, can be fabricated, with a highly porous and interconnected foam-like morphology. ${ }^{44-46}$ Nanofoams of different materials, such as carbon ${ }^{44,45}$ and metal oxides $\left(\mathrm{ZnO}, \mathrm{TiO}_{2}, \mathrm{SnO}_{2}\right.$ and $\left.\mathrm{MoO}_{3}\right),{ }^{46}$ have been produced by PLD.

Due to the progress in the study of nanostructured materials, the performance of supercapacitors has been continuously improved as a result of the larger surface area and better activity of electrode materials. However, the high specific surface area usually comes together with a low packing density, which results in a large volume occupancy of the produced devices. Huan Li et al. discussed the importance of volumetric capacitance $\left(C_{\mathrm{S}_{-} \mathrm{V}}\right)$ and studied methods to quantify the volumetric performance of supercapacitors. ${ }^{47}$ Zhuangnan Li et al. reported that a maximum $C_{\mathrm{s}_{-} \mathrm{V}}$ can be achieved when the pore sizes match the diameter of the electrolyte ions by tuning the interlayer spacing of freestanding graphene laminate films. ${ }^{48}$ Our group recently reported the production of MO nanofoams by PLD, which showed a very large specific surface area and a high specific capacitance as electrodes in supercapacitors. ${ }^{41}$ However, there are still several points which are unclear or can be improved for the understanding of the MO nanofoam: first, the MO nanofoam shows a large surface area but a small density, i.e., although its $C_{\mathrm{s}_{-} \mathrm{m}}$ is high, its $C_{\mathrm{s}_{-} \mathrm{V}}$ is quite low. Second, there is an activation process within the first 200 cycles whose mechanism is still not very clear. Last, there is still space to improve the mechanical properties by increasing the density and strengthening the connection between the MO nanoparticles that build the MO nanoform. As discussed above, $C_{\mathrm{s}_{-} \mathrm{m}}$ and $C_{\mathrm{S}_{-} \mathrm{V}}$ are closely related to the density and the specific surface area of the nanostructures, and hence high $C_{\mathrm{s}_{\mathrm{m}} \mathrm{m}}$ is usually accompanied with low $C_{\mathrm{s}_{-} \mathrm{V}}$ and vice versa. In order to obtain both high $C_{\mathrm{s}_{\_} \mathrm{m}}$ and $C_{\mathrm{s}_{\mathrm{V}} \mathrm{v}}$ in a supercapacitor, nanomaterials with a suitable density are desirable. However, it is still a challenge to produce nanostructures with a controlled particle and pore size. By using PLD, it is practically simple to change the pressure in the PLD chamber and consequently, to tune the density of the prepared nanostructures in a straightforward way. ${ }^{49-52}$ The oxidation state of the transition metal oxides prepared by this method is expected to be similar, and thus one can focus on the pure morphology effect on the supercapacitive properties.

In this work, we report on the synthesis and characterization of MO nanostructures by PLD with a tunable microstructure, driven by only one parameter: the background gas pressure. How the gas pressure affects the microstructure and the deposition rate will be discussed in this work. We aim at the fabrication of a suitable nanostructure showing both high $C_{\mathrm{s} \_\mathrm{m}}$ and $C_{\mathrm{s}_{-} \mathrm{V}}$. The purely morphological effect on the supercapacitive properties is the main objective of this investigation.

\section{Methods}

The MO nanofoam was prepared by PLD from a metallic Mn target in the presence of $\mathrm{O}_{2}$ with a pressure range of $0.1,0.5,1.0$ and 2.0 Torr at room temperature (the samples are named as MO01, MO05, MO10 and MO20). The deposition conditions and other parameters for the samples are listed in Table S1 in the ESI. $\dagger$ Target ablation was done using the first harmonic (1064 nm wavelength) of a pulsed Nd:YAG laser with $200 \mathrm{~mJ}$ energy of each pulse, $0.12 \mathrm{~J} \mathrm{~mm}^{-2}$ energy density, $7 \mathrm{~ns}$ pulse duration and $10 \mathrm{~Hz}$ repetition rate. The beam was focused onto the Mn target with an incidence angle of $45^{\circ}$ and the ablated Mn plume expanded in the direction of the substrate, which was mounted on a sample holder, at a fixed $3.5 \mathrm{~cm}$ distance from the target. Samples for structure and morphology studies were deposited over Si single crystal wafers (100) and samples for electrochemical studies were prepared over stainless-steel sheets as substrates, with the deposition time fixed for 30 minutes duration. The deposition rates were measured with a quartz crystal balance mounted inside the PLD vacuum chamber. The as-prepared samples were then heat-treated in air for 90 minutes at $300{ }^{\circ} \mathrm{C}$ in order to improve the mechanical bonding properties. The morphology and thickness of the samples were investigated with field-emission scanning electron microscopy (SEM: JEOL JSM 7100F). The chemical composition and the electronic structure of the products were characterized by Raman spectroscopy (Witec alpha 300 Raman spectrometer, $532 \mathrm{~nm}$ wavelength excitation) and X-ray photoelectron spectroscopy (XPS: a Thermo Scientific ESCALAB 250XI spectrometer with monochromatized $\mathrm{Mg}-\mathrm{K} \alpha$ radiation). A typical three-electrode glass cell equipped with a working electrode (stainless steel with manganese oxide deposited), a platinum foil counter electrode, and a $\mathrm{Ag} \mid \mathrm{AgCl}$ (3 M) reference electrode was used for electrochemical measurements. Cyclic voltammetry (CV) was performed using an electrochemical workstation (Ivium Technologies model: IviumnStat) in a $0.1 \mathrm{M}$ $\mathrm{Na}_{2} \mathrm{SO}_{4}$ aqueous solution.

\section{Results and discussion}

Fig. 1(a) shows the deposition rates of MO measured with the quartz balance. We could see that the deposition rates decreased with the increasing pressure. Fig. 1(c) and (d) illustrate the laser ablation process in vacuum and with the background gas in the chamber. When the laser pulse reached the target surface, it evaporated atoms and small clusters of the target material with a quite high speed inside the plasma plume and they could deposit on the substrate with plume expansion. In vacuum, the mean-free-path of the atoms is much higher than the target-substrate distance. As a result, the atoms could arrive at the substrate with very low collision 

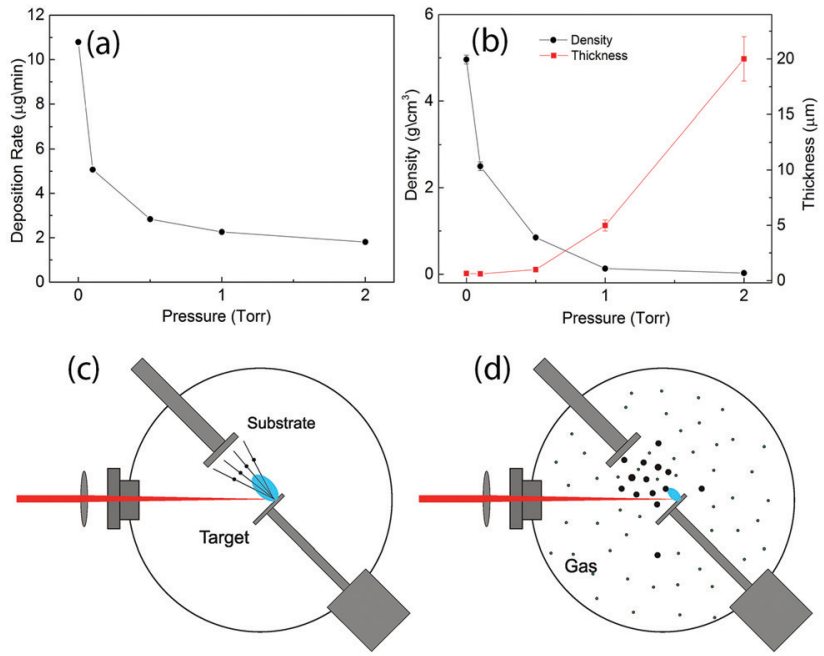

Fig. 1 (a) Deposition rates measured by the quartz balance as a function of pressure in the chamber. (b) Densities and thicknesses of the samples as a function of pressure. Schematic illustration of the deposition process (c) in vacuum and (d) with the background gas. The black dots in (c) and the bigger black dots in (d) indicate $\mathrm{Mn}$ atoms and nanoparticles, respectively. The smaller gray dots in (d) illustrate the gas molecules in the chamber.

probability [see Fig. 1(c)]. This process resulted in the formation of compact thin films. The presence of the gas in the chamber decreased the mean-free-path of the atoms and generated collisions and reactions between the ablated atoms and gas molecules. This process decreased the velocity of the atoms and those lower energy atoms interacted and consequently generated nanoparticles before they arrived at the substrate as shown in Fig. 1(d). Due to the collision processes, which led to plume scattering, the deposition rates decreased with the increasing pressure. The mass of the active materials on the electrodes was obtained with the deposition rates and the area of the electrodes.

From the above discussion we know that the pressure in the PLD chamber determines the microstructure of the deposited materials, for example, thin films can be obtained in vacuum ${ }^{53}$ and the nanofoam can be formed with 5 Torr of $\mathrm{O}_{2}{ }^{41}$ Thus, it is simple to tune the density of the deposited materials gradually by changing the pressure in the PLD chamber. For the samples prepared in this work, the thickness measured with the crosssection SEM images and the density calculated with the mass and the volume as a function of gas pressure are shown in Fig. 1(b). Their values can be found in Table S1 of the ESI. $\dagger$ A less thickness increase is observed when the pressure increased to 0.5 Torr. From then on, the thickness of the prepared material increased very rapidly with the increase of the pressure. The density of the samples, on the other hand, shows an opposite behavior. It shows a very fast decrease when the pressure changes from $10^{-6}$ Torr to 1 Torr. Since the main goal of this work is to study the morphology effect and consequently to find a suitable structure of MO with both high $C_{\mathrm{s}_{-} \mathrm{m}}$ and $C_{\mathrm{s}_{-} \mathrm{V}}$, the pressure range between 0 and 2 Torr is thus sufficient for the present study.

In this work, the presence of the background gas $\mathrm{O}_{2}$ served not only as collision media but also as a reaction source, resulting in

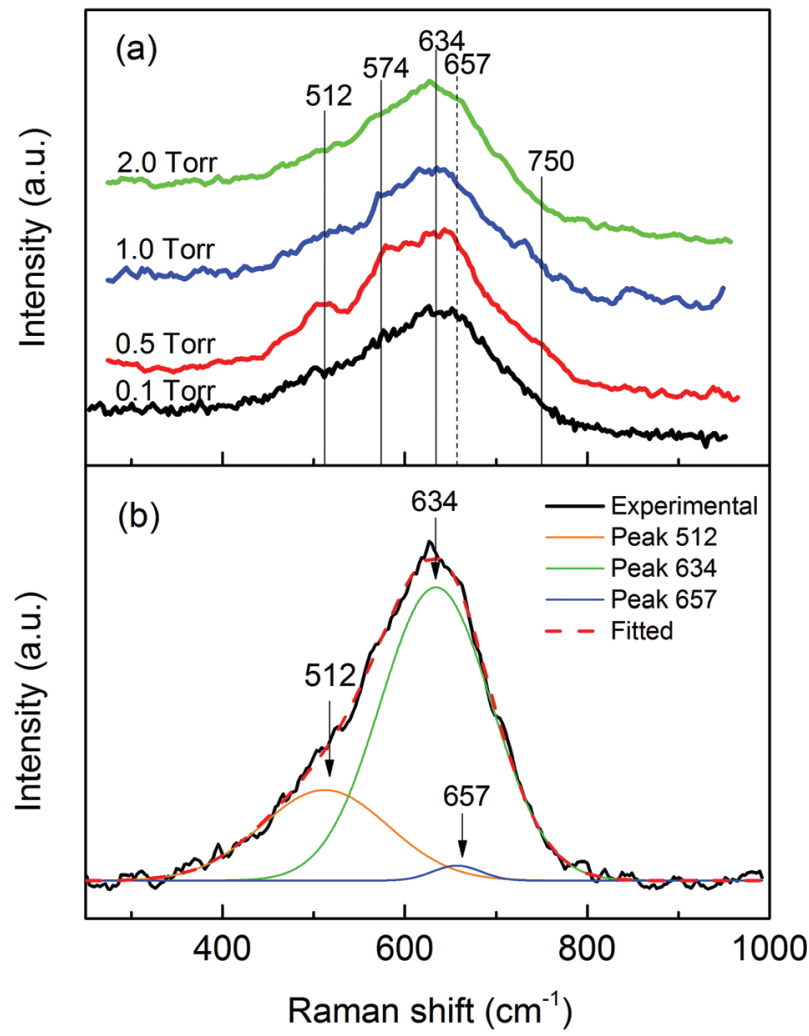

Fig. 2 (a) Raman spectra of the MO samples. The vertical lines indicate the position of the main peaks of $\alpha-\mathrm{MnO}_{2}$ (solid lines) and tetragonal $\mathrm{Mn}_{3} \mathrm{O}_{4}$ (dashed line). (b) Deconvolution of the main peak for the sample $\mathrm{MO} 20$.

the formation of MO nanoparticles. A complete understanding of the oxidation state of manganese was necessary, and therefore the electrical structures were studied with Raman spectroscopy and XPS.

Fig. 2(a) shows the most relevant portion of the Raman spectra obtained from the studied samples, since no features were observed at higher wavenumbers. The vertical lines in the graph designated the positions of $\alpha-\mathrm{MnO}_{2}$ (solid lines) and tetragonal $\mathrm{Mn}_{3} \mathrm{O}_{4}$ (dashed line). The spectra were similar and noisy, as can be observed. In fact, better spectra could be obtained with a higher laser power. However, the oxidation states were modified by stronger laser radiation in the major presence of $\mathrm{Mn}_{3} \mathrm{O}_{4}$. In this case, a very low laser density was applied during the spectrum collection and the accumulating time for each spectrum was more than 8 hours. Since all the spectra showed some features of the $\mathrm{MnO}_{2}$ Raman spectrum, we associated the weak spectra to the dominance of this oxide in the samples. In addition, the spectra were also compatible with the presence of $\mathrm{Mn}_{3} \mathrm{O}_{4}$, probably due to partial damage of the sample by the incident laser. The mean peak of MO20 was fitted with the Raman shift of $\mathrm{MnO}_{2}$ and $\mathrm{Mn}_{3} \mathrm{O}_{4}$ as shown in Fig. 2(b). This clearly demonstrated that most of the Raman scattering was from $\mathrm{MnO}_{2}\left(634 \mathrm{~cm}^{-1}\right.$ and $\left.512 \mathrm{~cm}^{-1}\right)$ and the intensity of the $\mathrm{Mn}_{3} \mathrm{O}_{4}\left(657 \mathrm{~cm}^{-1}\right)$ scattering was very low. However, the integrated intensity ratio of $\mathrm{MnO}_{2}$ and $\mathrm{Mn}_{3} \mathrm{O}_{4}$ does not correspond to the real proportion of the two oxides in 
the sample due to different Raman scattering probabilities for different manganese oxides. It is well known that $\mathrm{MnO}_{2}$ has a much smaller Raman activity, as compared to other manganese oxides. ${ }^{54}$ So there was even less $\mathrm{Mn}_{3} \mathrm{O}_{4}$ in the deposited material than what the Raman spectrum indicated. Considering the above discussion, we can conclude that the samples had very similar structures, majorly composed of $\mathrm{MnO}_{2}$.

Fig. 3 shows the XPS Mn 2p and O 1s spectra of the samples studied in this work. The Mn 2p spectra were placed at the same minimum background level, and normalized to the maximum intensity of the higher peak, in order to make the comparison easier. The O 1s spectra were, instead, Shirley background subtracted and normalized to the maximum intensity of the higher peak, for the same purpose. The Mn 2p spectra of the four samples were practically identical, with the Mn 2 $\mathrm{p}_{1 / 2}$ peak maximum located in the 642.2-642.25 eV region and the Mn 2 $\mathrm{p}_{3 / 2}$ peak maximum located in the 653.8-654.05 eV range. These peak positions were compatible with those reported for $\mathrm{a}-\mathrm{MnO}_{2}$ by $\mathrm{Gu}$ et al., ${ }^{55}$ at $644.2 \mathrm{eV}$ and $653.8 \mathrm{eV}$, respectively, in accordance with the Raman results. On the other hand, the $\mathrm{O}$ 1s spectra showed small to moderate differences in shape. To analyze them we should consider the presence of the O-Mn-O, Mn-O-H and $\mathrm{H}-\mathrm{O}-\mathrm{H}$ peaks located at about $529.7 \mathrm{eV}, \mathbf{5 3 0 . 5} \mathrm{eV}$ and $531.5 \mathrm{eV}$. In order to get information on the Mn oxidation state, we analyzed the $\mathrm{O} 1 \mathrm{~s}$ spectra by fitting the above-mentioned peaks to the Shirley background subtracted $\mathrm{O}$ 1s spectra (see the fitting results in the ESI $\dagger$ ). We estimated the Mn oxidation number by using the $\mathrm{O}-\mathrm{Mn}-\mathrm{O}$ and $\mathrm{Mn}-\mathrm{O}-\mathrm{H}$ and $\mathrm{H}-\mathrm{O}-\mathrm{H}$ peak areas, within the procedure suggested by Tholkappiyan et al. ${ }^{56}$ We obtained the oxidation numbers for the samples from 0.5 to 2 Torr to be equal to $2.8,2.7,2.9$, and 3.2 , respectively. The oxidation numbers of the three samples were situated in the $2.9 \pm 0.3$ range, constituting a relatively small variation. The expected value of the oxidation number for $\mathrm{MnO}_{2}$ should be near 4.0 and the origin of the smaller oxidation number in our samples is unclear. With the
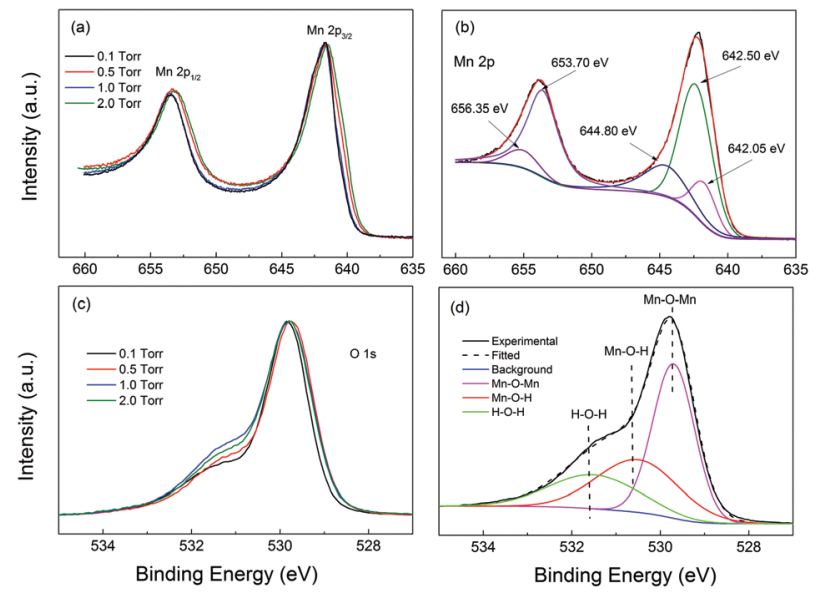

Fig. 3 (a) High resolution XPS spectra of $M n 2 p$ for the MO samples. (b) Deconvolution of the Mn 2p spectrum for MO10. (c) High resolution XPS spectra of $O 1 \mathrm{~s}$ for the samples. (d) Deconvolution of the $O 1 \mathrm{~s}$ spectrum for MO10. results we can conclude that the sampes had similar oxidation states, which was consistent with the minor difference observed in the Raman spectra and the Mn 2p XPS spectra. Apparently all the samples had very similar electronic structures and compositions.

The morphology of the MO nanostructures was investigated by SEM and the images are shown in Fig. 4. The surface of MO01 was quite flat with several spheres on top. The high resolution image revealed that the sample was formed by nanoparticles with size less than $10 \mathrm{~nm}$. The cross-section image showed that the film was still quite dense with a thickness of $\sim 600 \mathrm{~nm}$ although it was formed by nanoparticles. When the pressure increased to 0.5 Torr, the MO05 sample showed a very rough, cracked surface with big balls on it. From the high resolution image one could see that the surface had a cauliflower-like morphology, and that each big ball on the surface was constructed by nanoparticles. The observed cracks were the voids between the big balls. From the cross-section image one could see that the cracks came from the sample surface to the substrate, and the sample showed a perpendicular columnar structure with a $150 \mathrm{~nm}$ mean column diameter. The measured thickness was about $1 \mu \mathrm{m}$, bigger than that of MO01, which corresponds to the decreased density. With 1.0 Torr $\mathrm{O}_{2}$ pressure inside the chamber, the density of MO10 decreased even more. The surface of the sample still showed the presence of big balls as in MO05, but with a larger distance between the nanoparticles. The cross section image exhibited a tree-like structure in the perpendicular direction and the thickness reached about $5 \mu \mathrm{m}$. When the $\mathrm{O}_{2}$ pressure increased to 2.0 Torr, the microstructure was nanofoam-like with a very low density, as reported before. ${ }^{41}$ The nanofoam was constructed by nanofilaments, which were assemblies of nanoparticles. The thickness of this sample was as high as $\sim 25 \mu \mathrm{m}$ although it had less material compared with other samples. No obvious texture was observed in this sample. The thicknesses would be used to calculate the volumes of the active materials on the electrodes.

The mechanism of the different structure formation was as follows. As shown in Fig. 1(c), the vaporized atoms by the laser pulse possessed very high energy and they deposited directly onto the substrate. The impact of the atoms was very high, and furthermore the atoms could form chemical bonds only with the deposited materials on the substrate since most of the materials arriving at the substrate were single atoms. As a result, thin films could be obtained in vacuum. With the gas molecules in the chamber, as shown in Fig. 1(d), the collision among the atoms and gases greatly decreased the energy of the atoms and as a result, the atoms formed nanoparticles before reaching the substrate. At the same time, the velocity of the nanoparticles was much less than the single atoms in vacuum. The nanoparticles with less energy had much less impact energy on the substrate and this resulted in the formation of less dense materials than the thin films. With an even higher pressure, due to more scattering and an even lower velocity, the nanoparticles could move to different directions and they were able to find low energy positions, which were sharp points on 

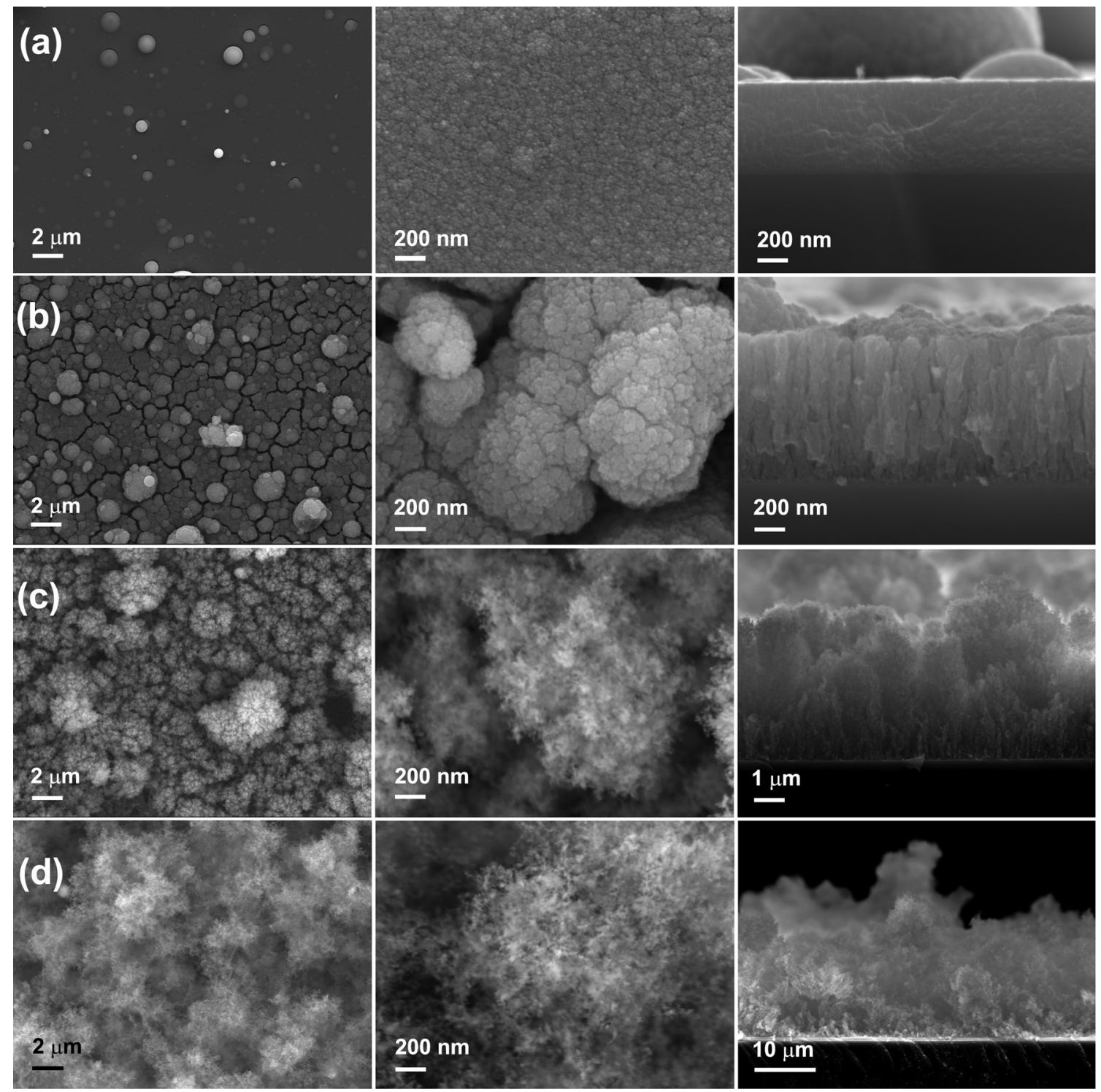

Fig. 4 SEM images of the MO nanostructures prepared by PLD with gas pressures of (a) 0.1 Torr, (b) 0.5 Torr, (c) 1.0 Torr and (d) 2.0 Torr. The left row is the low magnification; in the middle, the high magnification and the right, the cross-section images.

the surface. The sharp ends on the surface always have a higher statistic charge to attract the nanoparticles during deposition. As a result, the nanoparticles formed filaments, and furthermore nanofoams. Detailed microstructural studies demonstrate a crystalline structure of similar MO samples. ${ }^{41}$

After understanding the morphology and the oxidation states, we studied the supercapacitive properties by cyclic voltammetry (CV) in a $0.1 \mathrm{M} \mathrm{Na}_{2} \mathrm{SO}_{4}$ aqueous solution with a three-electrode system. The representative $\mathrm{CV}$ curves of the MO electrodes over a range of scan rates from 5 to $350 \mathrm{mV} \mathrm{s}^{-1}$ could be found in the ESI. $\dagger$ The CV curves exhibited typical charge and discharge hysteresis as we expected, indicating the kinetic reversibility of the redox process. We estimated the capacitive behaviors of the MO electrode from the CV curves, by calculating the charge during the anodic and cathodic scan. The calculated $C_{\mathrm{S} \_\mathrm{m}}$ and $C_{\mathrm{S} \_\mathrm{V}}$ values are shown in Fig. 5 . The four samples demonstrated a huge $C_{\mathrm{s} \_\mathrm{m}}$ difference both at low and high scan rates, with variations from 200 to $1000 \mathrm{~F} \mathrm{~g}^{-1}$ at a scan rate of $5 \mathrm{mV} \mathrm{s}^{-1}$ and 30 to $300 \mathrm{~F} \mathrm{~g}^{-1}$ at $350 \mathrm{mV} \mathrm{s}^{-1}$, as shown in Fig. 5(a). The MO01 showed the lowest $C_{\mathrm{s} \_\mathrm{m}}$ value in the range of all the scan rates. The $C_{\mathrm{s} \_\mathrm{m}}$ of MO20 was much higher than that of MO01 but lower than those of both MO05 and MO10. The two samples, namely, MO05 and MO10, showed a high $C_{\mathrm{S} \_\mathrm{m}}$ value but with a different behavior as a function of scan rate. With the scan rates ranging from 5 to $25 \mathrm{mV} \mathrm{s}^{-1}$, the MO05 had higher $C_{\mathrm{S} \_\mathrm{m}}$ than MO10 and above $25 \mathrm{mV} \mathrm{s}^{-1}$, the MO10 became better and the $C_{\mathrm{s} \_\mathrm{m}}$ value $\left(315 \mathrm{~F} \mathrm{~g} \mathrm{~g}^{-1}\right.$ ) was $60 \%$ higher than that of MO05 $\left(190 \mathrm{~F} \mathrm{~g}^{-1}\right)$ at a scan rate of $350 \mathrm{mV} \mathrm{s}^{-1}$.

The $C_{\mathrm{s}_{-} \mathrm{v}}$ values, however, showed very different behavior compared with the $C_{\mathrm{s} \_\mathrm{m}}$ value, as shown in Fig. 5(b). The volume of each sample was obtained by the area and thickness of the active material and the values can be found in Table S1 of 


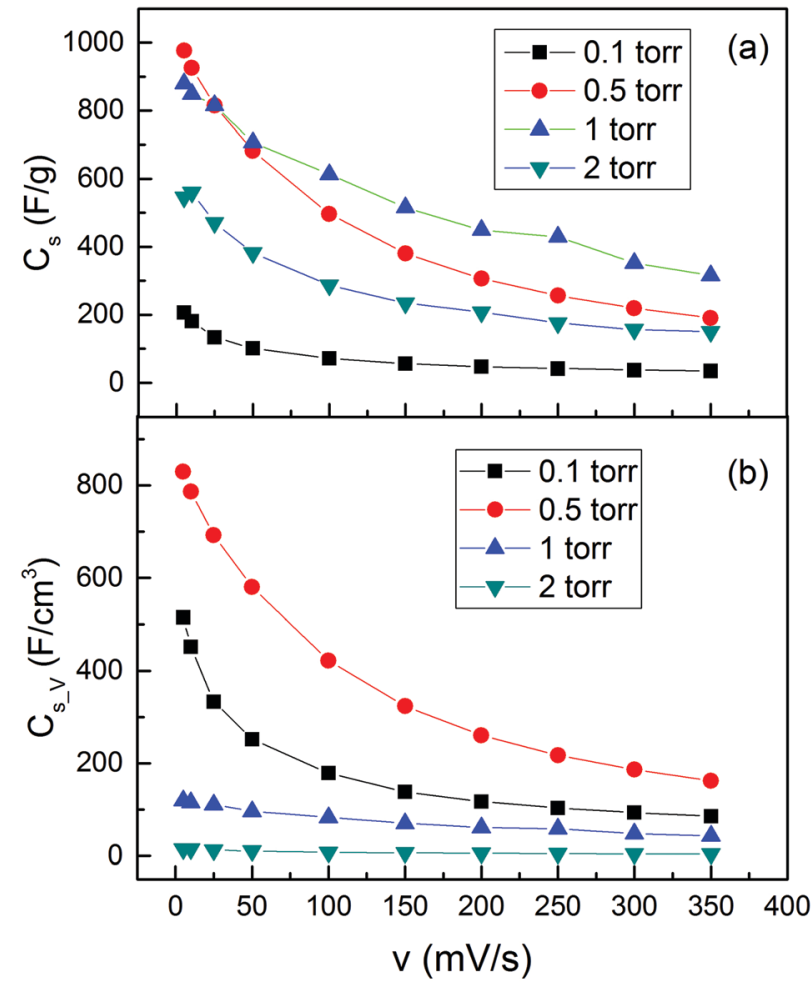

Fig. 5 (a) Gravimetric capacitance $\left(C_{s_{-} m}\right)$ and (b) volumetric capacitance $\left(C_{s_{-} v}\right)$ as a function of voltage scan rate for the $\mathrm{MO}$ nanostructures.

the ESI. $\dagger$ Although MO20 had a very high $C_{\mathrm{S}_{\mathrm{B}} \mathrm{m}}$, it had the lowest $C_{\text {s_v }}$ due to the sponge-like morphology with an extremely low density. MO10 exhibited the highest $C_{\mathrm{s}_{\mathrm{B}} \mathrm{m}}$ above the voltage scan rate of $50 \mathrm{mV} \mathrm{s}^{-1}$; however, it had even lower $C_{\mathrm{S}_{-} \mathrm{V}}$ than that of MO01, the one with the lowest $C_{\mathrm{s}_{-} \mathrm{m}}$. The highest $C_{\mathrm{S}_{-} \mathrm{V}}$ was found in the sample MO05, which had the highest $C_{\mathrm{s}_{\mathrm{m}} \mathrm{m}}$ below the voltage scan rate of $50 \mathrm{mV} \mathrm{s}^{-1}$ as well. A comparison of the MO01 and MO05 samples in Fig. 5(b) shows that the $C_{\mathrm{S}_{-} \mathrm{V}}$ of MO01 decreased much faster than that of MO05, for example, from $515 \mathrm{~F} \mathrm{~cm}^{-3}$ at $5 \mathrm{mV} \mathrm{s}^{-1}$ to $251 \mathrm{~F} \mathrm{~cm}^{-3}$ at $50 \mathrm{mV} \mathrm{s}^{-1}$ for MO01, it decreased by more than $50 \%$. The $C_{\mathrm{s}_{-} \mathrm{V}}$ values were $830 \mathrm{~F} \mathrm{~cm}^{-3}$ at $5 \mathrm{mV} \mathrm{s}^{-1}$ and $580 \mathrm{~F} \mathrm{~cm}^{-3}$ at $50 \mathrm{mV} \mathrm{s}^{-1}$ for MO05, and decreased by only $\sim 30 \%$.

Usually the theoretical values of the specific capacitance are determined by the intrinsic properties of the active electrode materials for supercapacitors. The real specific capacitance, on the other hand, depends strongly on the morphologies. In this work, the MO samples are all with similar oxidation states, as can be derived from the Raman and XPS spectra. The most robust difference for them is the morphology, and therefore the different $C_{\mathrm{S} \_\mathrm{m}}$ and $C_{\mathrm{S} \_\mathrm{V}}$ values observed in the present work are closely related to the morphologies of the different nanostructures. In order to get a better understanding, we separated the electrical double layer capacitance (EDLC) and the diffusion controlled pseudocapacitance for the three typical electrodes with the Trasatti method ${ }^{57-59}$ and for different voltage scan rates with the Dunn method. ${ }^{60,61}$ The results are presented in Fig. 6, together with schematic illustrations of the three typical
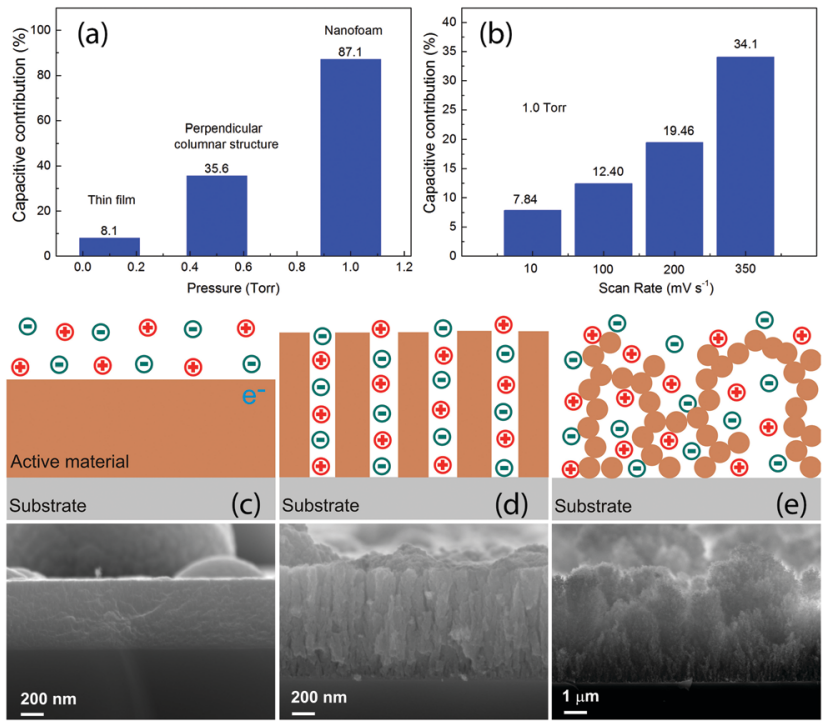

Fig. 6 (a) Capacitive contribution for the samples representing the three typical nanostructures. (b) Capacitive contribution at different voltage scan rates for MO10, which has a nanofoam structure. Schematic illustration of the electrodes for (c) MO01, (d) MO05 and (e) MO10 with different morphologies of the active materials, as indicated by the SEM images below. The circles with + and - signals inside indicate positive and negative ions.

corresponding microstructures observed in this work. The detailed calculations can be found in the ESI. $\dagger$ As can be seen in Fig. 6(a), the capacitive contribution significantly increased from $8.1 \%$ for the thin film sample MO01 to $87.1 \%$ for the nanofoam sample MO10. By changing the scan rates, for example, in MO10 as shown in Fig. 6(b), the capacitive contribution increased upon increasing the voltage scan rate, from $\sim 8 \%$ with a scan rate of $10 \mathrm{mV} \mathrm{s}^{-1}$ to $\sim 34 \%$ with a scan rate of 350. The values shown in Fig. 6(a) were obtained by the Trasatti Method under the conditions of the voltage scan rate $v \rightarrow 0$ and $v \rightarrow \infty$ and that is why they are different from the results for the intermediate scan rates shown in Fig. 6(b), which have been calculated with the Dunn method. The significant increase of the capacitive contribution in this work is due to the increase of the specific surface areas for the different nanostructures, as can be clearly seen from the SEM images. The values of the specific surface area vary from several $\mathrm{m}^{2}$ for the thin films (estimated by supposing a thin film with $600 \mathrm{~nm}$ of thickness) to $\sim 150 \mathrm{~m}^{2}$ for the nanofoam measured by $\mathrm{N}_{2}$ adsorption. ${ }^{41}$ We will discuss the detailed morphology effects further on the capacitive contribution in the three nanostructures.

As is well known, there are two different processes for the charge storage mechanism for MO-based supercapacitors: capacitive contribution associated with the adsorption/ desorption $(\mathrm{a} / \mathrm{d})$ process that occurs at the electrode surface and/or diffusion controlled contribution associated with the insertion/extraction (i/e) process that happens in the electrode bulk. ${ }^{62,63}$ The a/d process dominates in the MO samples with a high surface area, whereas the i/e process occurs mostly in crystalline MO compounds. ${ }^{62,63}$ For $2 \mathrm{D}$ materials with only one dimension in the nanometer scale, such as thin films, as shown in Fig. 6(c), the positive and negatives ions were in touch with 
the active materials only from one side. Such a configuration had a less surface area, which leads to less capacitive contribution and diffusion controlled pseudocapacitance dominates. As a result, it had the lowest $C_{\mathrm{s} \_\mathrm{m}}$. Since the active material was quite dense, the $C_{\mathrm{s}_{-} \mathrm{v}}$ of such a sample was not as bad as $C_{\mathrm{s} \_\mathrm{m}}$.

The perpendicular columnar structure, as shown in Fig. 6(d), had a higher specific surface area than the thin films. The positive and negative ions were surrounding each pillar in this configuration. The mean diameter of the pillars was smaller than the thickness of the thin films as shown in Fig. 6(c). Thus, the i/e process of ions became much easier. Together with the high surface area, which favors the charge a/d process, the perpendicular columnar structures had a much higher $C_{\mathrm{s} \_\mathrm{m}}$ value. Since the density of the material decreased but not much, $C_{\mathrm{s}_{-} \mathrm{V}}$ was the highest among all the samples as well. Since all the pillars were connected with the substrate, the charge transfer path from the active materials to the substrate was short as well and almost all the materials participated in the charge/discharge process.

The foam like structures, as shown in Fig. 6(e), had a much higher specific surface area and lower density than the other structures. Each nanoparticle was in contact with positive and negative ions. With the mean diameter of the nanoparticles being much smaller than the diameter of the pillars as shown in Fig. 6(d), both of the a/d and i/e processes of the ions in the foam-like structure were the easiest among the three configurations. Due to large surface areas, this sample shows the highest capacitive contribution and for such a reason, MO10 had the highest $C_{\mathrm{S}_{\mathrm{m}} \mathrm{m}}$ with voltage scan rates bigger than $50 \mathrm{mV} \mathrm{s}^{-1}$. Due to bad contacts between the nanoparticles constructing the filaments, some of them might not participate in the charge/discharge process and as a result, the $C_{\mathrm{s}_{-} \mathrm{m}}$ values of this nanostructure were lower than those of the columnar structures with a voltage scan rate lower than $50 \mathrm{mV} \mathrm{s}^{-1}$. The foam-like structure had an extremely low density, which resulted in a significant decrease of $C_{\mathrm{s}_{-} \mathrm{V}}$. Usually one would expect much higher $C_{\mathrm{s}_{-} \mathrm{m}}$ for the nanofoam samples, namely, MO10 and MO20. In this work, the $C_{\text {s_m }}$ value was calculated by using the total mass of the MO for each electrode. For MO10 and MO20, although part of the nanoparticles was assumed to not participate in the charge/discharge processes, their mass was still included in the calculation. As a result, lower values of $C_{\text {s_m }}$ were obtained for the nanofoam samples.

Compared with the results in the literature, the $C_{\mathrm{s} \mathrm{m}}$ and $C_{\mathrm{s} \_\mathrm{V}}$ values of the $\mathrm{MnO}$ thin film and the nanofoam were normal, as shown in Fig. 7. The MO thin film had moderate $C_{\mathrm{s} \_\mathrm{V}}$ but low $C_{\mathrm{s} \_\mathrm{m}}$ and the nanofoam was opposite. The $C_{\mathrm{s} \_\mathrm{m}}$ value in the thin film structure $\left(205 \mathrm{~F} \mathrm{~g}^{-1}\right.$ at $\left.5 \mathrm{mV} \mathrm{s}^{-1}\right)$ in this work was similar to the reported value $\left(298 \mathrm{~F} \mathrm{~g}^{-1}\right.$ at $\left.0.5 \mathrm{~mA} \mathrm{~cm}^{-2}\right) .^{74}$ The most astonishing result was obtained from the sample with a perpendicular columnar structure, with the maximum $C_{\mathrm{s} \_\mathrm{m}}$ value of $976 \mathrm{~F} \mathrm{~g}^{-1}$ and a $C_{\mathrm{S}_{-} \mathrm{V}}$ value of $830 \mathrm{~F} \mathrm{~cm}^{-3}$ at $5 \mathrm{mV} \mathrm{s}^{-1}$. Although none of the values were the best as shown in Fig. 7, the combination of both high $C_{\mathrm{s}_{-} \mathrm{m}}$ and $C_{\mathrm{s}_{-} \mathrm{V}}$ was very significant. It showed a much higher $C_{\mathrm{S} \_\mathrm{m}}$ than that of the pure MO nanofibers $\left(526 \mathrm{~F} \mathrm{~g}^{-1}\right.$ at $\left.0.5 \mathrm{~mA} \mathrm{~cm}^{-2}\right),{ }^{75}$ and moreover, even slightly higher

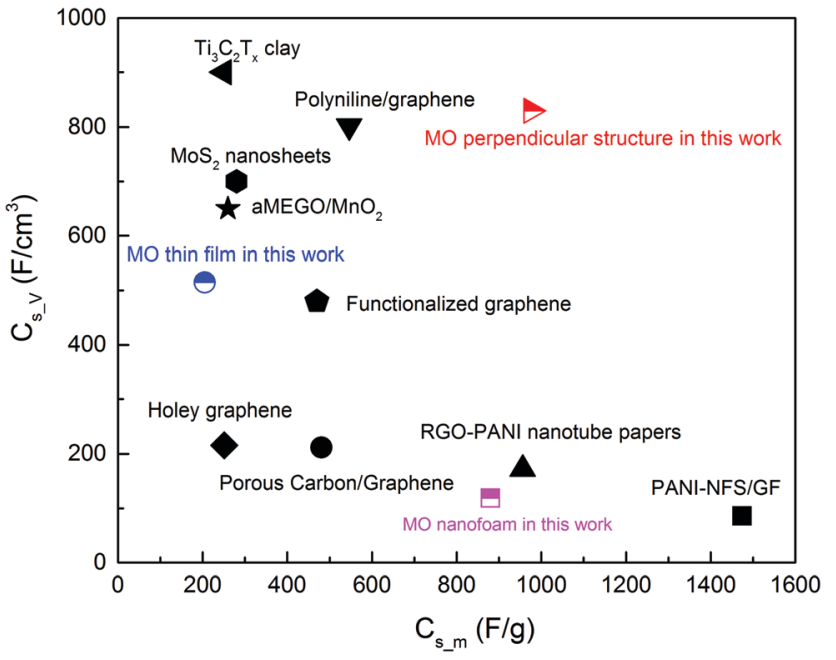

Fig. 7 Comparison of the $C_{s_{s} m}$ and $C_{s} \vee$ of the $M O$ nanostructures with other materials repoted in the literature, such as polyaniline/graphene composites, ${ }^{64} \mathrm{Ti}_{3} \mathrm{C}_{2} \mathrm{~T}_{x}$ clay, ${ }^{65} \mathrm{MoS}_{2}$ nanosheets, ${ }^{66}$ functionalized graphene sheets, ${ }^{67}$ porous carbon layer/graphene, ${ }^{68}$ RGO-F/PANI nanotube papers, ${ }^{69}$ aMEGO/MnO${ }_{2}{ }^{70}$ PANI-NFS/GF, ${ }^{71}$ porous carbon/grapnhene composites $^{72}$ and holey graphene. ${ }^{73}$

than that of the $\mathrm{MO} /$ graphene oxide composites $\left(729 \mathrm{~F} \mathrm{~g}^{-1}\right.$ at $\left.5 \mathrm{mV} \mathrm{s}^{-1}\right) .{ }^{76}$ The $C_{\mathrm{s}_{-} \mathrm{V}}$ value of the same sample $\left(830 \mathrm{~F} \mathrm{~cm}^{-3}\right.$ at $5 \mathrm{mV} \mathrm{s}^{-1}$ ) was superior to that for a 2D titanium carbide film decorated with manganese oxide nanoparticles as well $\left(602 \mathrm{~F} \mathrm{~cm}^{-3}\right.$ at $2 \mathrm{mV} \mathrm{s}^{-1}$ and $480 \mathrm{~F} \mathrm{~cm}^{-3}$ at $\left.5 \mathrm{mV} \mathrm{s}^{-1}\right) .{ }^{77}$ The highest $C_{\mathrm{s} \_\mathrm{m}}$ value in this work was slightly lower than that for the samples prepared at 5 Torr by $\mathrm{PLD}^{41}$ and the reason can be due to the different oxidation states of the Mn ions (can be seen from the Raman spectra).

In the MO electrodes prepared by PLD with an $\mathrm{O}_{2}$ pressure of 5 Torr, ${ }^{41}$ a significant increase of $C_{\mathrm{s} \_\mathrm{m}}$ was observed during the life-cycle tests. The normal capacitance increase at the early stage of the cycles due to the activation effect $^{78,79}$ cannot explain such a big change. This has been interpreted as a result of the contact improvement between nanoparticles during the charge/discharge cycles. With the four samples prepared in different $\mathrm{O}_{2}$ pressures and persisting distinct microstructures, we did further investigation on the $C_{\mathrm{s} \_\mathrm{m}}$ increase at the beginning of the life-cycle tests. The cycling test was carried out at $50 \mathrm{mV} \mathrm{s}^{-1}$ for 500 cycles. The $\mathrm{CV}$ curves for MO20 and $C_{\mathrm{s} \_\mathrm{m}}$ as a function of cycle numbers for all the samples are presented in Fig. 6. Other CV curves could be found in the ESI. $\dagger$ From Fig. 8(a) one could see clearly the modifications of the CV curves with the increase of the cycle numbers (indicated by the arrow in the figure). The current at a voltage higher than $0.8 \mathrm{~V}$ continuously decreased. On the contrary, the current between 0.2 and $0.8 \mathrm{~V}$ in the upper branch and between 0 and $0.6 \mathrm{~V}$ in the lower branch increased more significantly than the current decrease with a voltage above $0.8 \mathrm{~V}$. As a result, the area in the $\mathrm{CV}$ curves increased with the increase of the cycle numbers. The same effect was observed in MO10 but it was much weaker. The CV curves of the other two samples, MO01 and MO05, did not show such a modification (see the ESI $\dagger$ ). 

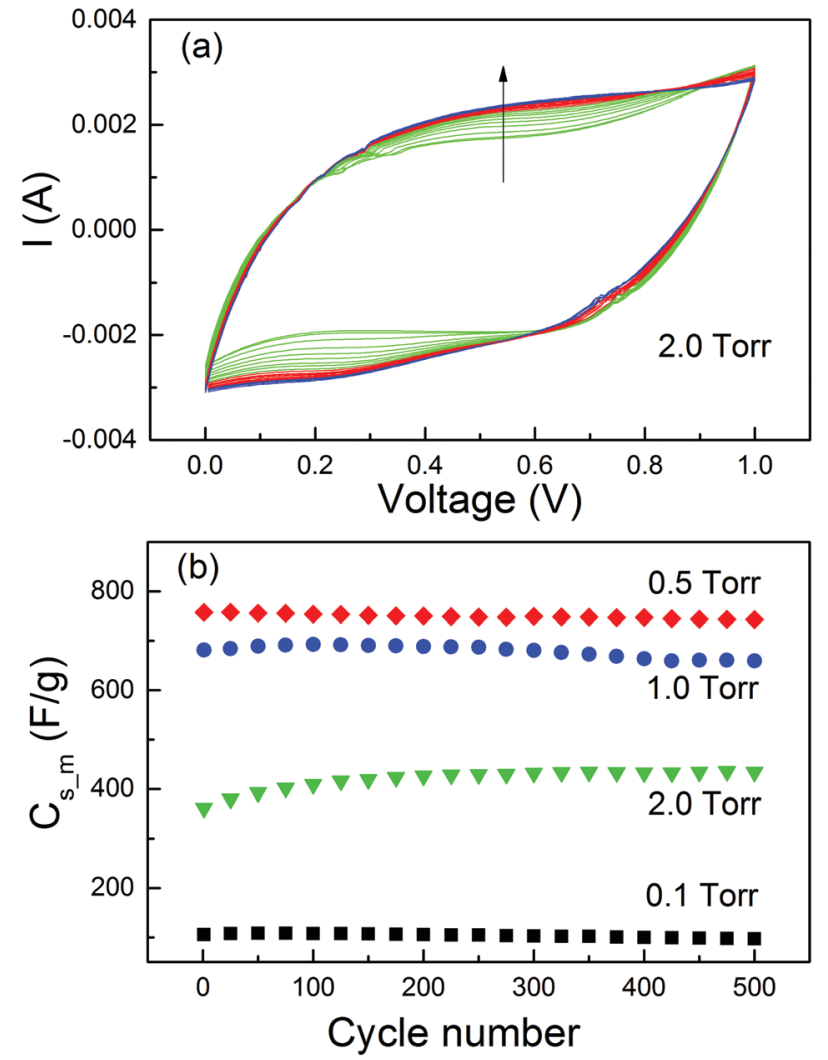

Fig. 8 (a) Cycling stability profile for $\mathrm{MO} 20$ at a voltage scan rate of $50 \mathrm{mV} \mathrm{s}^{-1}$. The arrow indicates the increase of cycle numbers from 1 to 500 . (b) $C_{\mathrm{s} \_m}$ at different cycle numbers from 1 to 500 cycles.

The $C_{\mathrm{s} \_\mathrm{m}}$ values obtained from the $\mathrm{CV}$ curves are plotted in Fig. 8(b). No $C_{\mathrm{s}_{\_} \mathrm{m}}$ increase was observed for the samples MO01 and MO05. The $C_{\mathrm{s}_{-} \mathrm{m}}$ values increased by only $\sim 1 \%$ for MO10 from cycle 1 to cycle $200\left(681 \mathrm{~F} \mathrm{~g}^{-1}\right.$ to $\left.689 \mathrm{~F} \mathrm{~g}^{-1}\right)$ and by more than $18 \%$ for MO20 (from $361 \mathrm{~F} \mathrm{~g}^{-1}$ to $426 \mathrm{~F} \mathrm{~g}^{-1}$ ). Both of them were much smaller than that for the sample prepared in 5 Torr of $\mathrm{O}_{2},{ }^{41}$ in which the $C_{\mathrm{s}_{-} \mathrm{m}}$ value increases by more than $100 \%$ from cycle 1 to cycle 200 . The results clearly indicated that the increase of $C_{\mathrm{s}_{\_} \mathrm{m}}$ was closely related with the morphology of the active material on the electrodes. For the thin films and perpendicular columnar structures, all MOs had good contact with the substrate and consequently, no $C_{\mathrm{s}_{\mathrm{m}} \mathrm{m}}$ increase was observed. The phenomenon occurred only in the samples with foam-like microstructures. However, the percentage of increase was related to the $\mathrm{O}_{2}$ pressure during deposition, which determines the density of the MO nanofoam. The higher the pressure of the $\mathrm{O}_{2}$ atmosphere, the lower the density and weaker contact between the nanoparticles. Structural modification accompanied with the loss of conductive pathways during the $\mathrm{i} / \mathrm{e}$ process induced by mechanical stress normally leads to a capacitance decrease.$^{80}$ In our case, the i/e process of the ions during charge/discharge cycles induced a mechanical pressure on the active materials and such a pressure had a much stronger effect on the samples with lower density and weaker contacts. As a result, a $C_{\mathrm{s} \_\mathrm{m}}$ increase in the foam-like samples was observed. The long-term stability of the MO electrodes should be tested for up to at least 5000 cycles. However, due to the great difficulty of access to laboratories during this time, we could not perform the experiment.

\section{Conclusions}

In summary, we prepared MO nanostructures by PLD in different $\mathrm{O}_{2}$ pressures with a metallic $\mathrm{Mn}$ target. The deposition rates decreased with the increase of the $\mathrm{O}_{2}$ pressure. Different microstructures were obtained for the MO samples, from thin films to perpendicular columnar structures and eventually to extra-low density nanofoams. The prepared nanomaterials were investigated as supercapacitor electrodes. The microstructures had a great effect on supercapacitor properties. The EDLC contribution increased significantly when the nanostructures changed from thin films to nanofoams due to the increase of the specific surface area. The thin film had the lowest $C_{\mathrm{s}_{-} \mathrm{m}}$ value but a quite high $C_{\mathrm{s}_{\mathrm{V}}}$ because of the high density. The electrode with a perpendicular columnar structure showed both high $C_{\mathrm{s}_{\mathrm{B}} \mathrm{m}}\left(976 \mathrm{~F} \mathrm{~g}^{-1}\right)$ and $C_{\mathrm{S}_{-} \mathrm{V}}$ and $(830 \mathrm{~F}$ $\mathrm{cm}^{-3}$ ), suggesting a good choice for most of the applications of supercapacitors. The foam-like structure with extra-low densities exhibited the best performance with fast charge/ discharge rates. For some special applications with respect to the high charge/discharge rates and no limitation of the volume, the MO nanofoam could be a good candidate. The life-cycle test showed that there was an activation effect for the MO nanofoams and the effect was stronger with the lower density MO nanomaterials. We concluded that the mechanical pressure induced by the ion i/e process during charge/discharge improved the contacts between the MO nanoparticles and as a result, the $C_{\mathrm{s}_{\mathrm{m}} \mathrm{m}}$ increased after several cycles. The stability for more cycles still needs further investigation to study the morphology effect on the mechanical stability of the electrodes. Our results showed clearly the pure morphology effect on the supercapacitive properties of the MO nanostructures and hence might benefit the material design for supercapacitor electrodes.

\section{Conflicts of interest}

There are no conflicts to declare.

\section{Acknowledgements}

The authors gratefully acknowledge FAPERJ for the support with grant numbers of E-26/202.790/2015, E-26/010.000978/ 2019 and E-26/010.001550/2019. This study was also supported, in part, by the Coordenação de Aperfeiçoamento de Pessoal de Nível Superior - Brasil (CAPES) - Finance Code 001.

\section{Notes and references}

1 D. P. Dubal, O. Ayyad, V. Ruiz and P. Gómez-Romero, Chem. Soc. Rev., 2015, 44, 1777-1790. 
2 Z. Yu, L. Tetard, L. Zhai and J. Thomas, Energy Environ. Sci., 2015, 8, 702-730.

3 Poonam, K. Sharma, A. Arora and S. Tripathi, J. Energy Storage, 2019, 21, 801-825.

4 Y.-Z. Wang, X.-Y. Shan, D.-W. Wang, H.-M. Cheng and F. Li, J. Energy Chem., 2019, 38, 214-218.

5 Z. Yang, J. Tian, Z. Yin, C. Cui, W. Qian and F. Wei, Carbon, 2019, 141, 467-480.

6 W. Zhang, C. Xu, C. Ma, G. Li, Y. Wang, K. Zhang, F. Li, C. Liu, H.-M. Cheng, Y. Du, N. Tang and W. Ren, Adv. Mater., 2017, 29, 1701677.

7 T. Zhu, J. Zhou, Z. Li, S. Li, W. Si and S. Zhuo, J. Mater. Chem. A, 2014, 2, 12545-12551.

8 Z. Qiu, Y. Wang, X. Bi, T. Zhou, J. Zhou, J. Zhao, Z. Miao, W. Yi, P. Fu and S. Zhuo, J. Power Sources, 2018, 376, 82-90.

9 G. A. Snook, P. Kao and A. S. Best, J. Power Sources, 2011, 196, 1-12.

10 X. Wu, W. Xing, L. Zhang, S. Zhuo, J. Zhou, G. Wang and S. Qiao, Powder Technol., 2012, 224, 162-167.

11 C. Lokhande, D. Dubal and O.-S. Joo, Curr. Appl. Phys., 2011, 11, 255-270.

12 J. Hao, S. Peng, H. Li, S. Dang, T. Qin, Y. Wen, J. Huang, F. Ma, D. Gao, F. Li and G. Cao, J. Mater. Chem. A, 2018, 6, 16094-16100.

13 K. S. Bhat and H. S. Nagaraja, Mater. Res. Express, 2018, 5, 105504.

14 R. Hou, G. S. Gund, K. Qi, P. Nakhanivej, H. Liu, F. Li, B. Y. Xia and H. S. Park, Energy Storage Mater., 2019, 19, 212-241.

15 D.-G. Wang, Z. Liang, S. Gao, C. Qu and R. Zou, Coord. Chem. Rev., 2020, 404, 213093.

16 D. Shanbhag, K. Bindu, A. Aarathy, M. Ramesh, M. Sreejesh and H. Nagaraja, Mater. Today Energy, 2017, 4, 66-74.

17 K. S. Bhat and H. Nagaraja, Electrochim. Acta, 2019, 302, 459-471.

18 J. Jiang and A. Kucernak, Electrochim. Acta, 2002, 47, 2381-2386.

19 A. González, E. Goikolea, J. A. Barrena and R. Mysyk, Renewable Sustainable Energy Rev., 2016, 58, 1189-1206.

20 W. Wei, X. Cui, W. Chen and D. G. Ivey, Chem. Soc. Rev., 2011, 40, 1697-1721.

21 C.-C. $\mathrm{Hu}$ and T.-W. Tsou, Electrochem. Commun., 2002, 4, 105-109.

22 B. Messaoudi, S. Joiret, M. Keddam and H. Takenouti, Electrochim. Acta, 2001, 46, 2487-2498.

23 Q.-Z. Zhang, D. Zhang, Z.-C. Miao, X.-L. Zhang and S.-L. Chou, Small, 2018, 14, 1702883.

24 Y. Dai, K. Wang and J. Xie, Appl. Phys. Lett., 2007, 90, 104102.

25 B. Li, X. Zhang, J. Dou and C. Hu, Ceram. Int., 2019, 45, 16297-16304.

26 Y.-H. Son, P. T. M. Bui, H.-R. Lee, M. S. Akhtar, D. K. Shah and O.-B. Yang, Coatings, 2019, 9, 631.

27 X. Zhao, B. M. Sánchez, P. J. Dobson and P. S. Grant, Nanoscale, 2011, 3, 839-855.
28 M. Aghazadeh, M. Ghannadi Maragheh, M. R. Ganjali and P. Norouzi, RSC Adv., 2016, 6, 10442-10449.

29 Y. Wang and I. Zhitomirsky, Langmuir, 2009, 25, 9684-9689. 30 D. Yang, J. Power Sources, 2012, 198, 416-422.

31 R. N. Reddy and R. G. Reddy, J. Power Sources, 2003, 124, 330-337.

32 J. Jiang, J. Li, X. Long, D. Zhao, K. Su, D. Xv, C. Yang and D. Qian, Mater. Res. Bull., 2019, 109, 29-33.

33 D. Yan, Z. Guo, G. Zhu, Z. Yu, H. Xu and A. Yu, J. Power Sources, 2012, 199, 409-412.

34 M. Jana, S. Saha, P. Samanta, N. C. Murmu, N. H. Kim, T. Kuila and J. H. Lee, J. Power Sources, 2017, 340, 380-392.

35 B. S. Singu, S. E. Hong and K. R. Yoon, J. Energy Storage, 2019, 25, 100851.

36 Y. Wang, C. Chen, X. Ding, L. Chu, Z. Deng, W. Liang, J. Chen and G. Fu, Laser Part. Beams, 2011, 29, 105-111.

37 H. Luna, D. F. Franceschini, R. Prioli, R. B. Guimarães, C. M. Sanchez, G. P. Canal, M. D. L. Barbosa and R. M. O. Galvão, J. Vac. Sci. Technol., A, 2010, 28, 1092-1098. 38 F. Fabris, Y. T. Xing, D. F. Franceschini, D. R. Sanchez, M. Alzamora and W. C. Nunes, J. Appl. Phys., 2017, 122, 063901.

39 S. Isber, E. Majdalani, M. Tabbal, T. Christidis, K. Zahraman and B. Nsouli, Thin Solid Films, 2009, 517, 1592-1595.

40 C.-C. Hu, C.-Y. Hung, K.-H. Chang and Y.-L. Yang, J. Power Sources, 2011, 196, 847-850.

41 J. N. Lacerda, D. F. Franceschini, E. A. Ponzio, L. M. Esteves, R. B. Guimaraes and Y. T. Xing, Mater. Chem. Phys., 2020, 242, 122459.

42 H. Wang, Y. Wang and X. Wang, New J. Chem., 2013, 37, 869-872.

43 D. Yang, J. Power Sources, 2011, 196, 8843-8849.

44 A. Rode, E. Gamaly and B. Luther-Davies, Appl. Phys. A: Mater. Sci. Process., 2000, 70, 135.

45 A. Zani, D. Dellasega, V. Russo and M. Passoni, Carbon, 2013, 56, 358-365.

46 G. Atanasova, A. O. Dikovska, T. Dilova, B. Georgieva, G. Avdeev, P. Stefanov and N. Nedyalkov, Appl. Surf. Sci., 2019, 470, 861-869.

47 H. Li, C. Qi, Y. Tao, H. Liu, D.-W. Wang, F. Li, Q.-H. Yang and H.-M. Cheng, Adv. Energy Mater., 2019, 9, 1900079.

48 Z. Li, S. Gadipelli, H. Li, C. A. Howard, D. J. L. Brett, P. R. Shearing, Z. Guo, I. P. Parkin and F. Li, Nat. Energy, 2020, 5, 160-168.

49 J. Avila-Avendano, I. Mejia, H. N. Alshareef, Z. Guo, C. Young and M. Quevedo-Lopez, Thin Solid Films, 2016, 608, 1-7.

50 N. R. C. Raju, K. J. Kumar and A. Subrahmanyam, J. Phys. D: Appl. Phys., 2009, 42, 135411.

51 J. N. Zeng, J. K. Low, Z. M. Ren, T. Liew and Y. F. Lu, Appl. Surf. Sci., 2002, 197-198, 362-367.

52 M. Ghidelli, L. Mascaretti, B. R. Bricchi, A. Zapelli, V. Russo, C. S. Casari and A. L. Bassi, Appl. Surf. Sci., 2018, 434, 1064-1073.

53 H.-U. Krebs, M. Weisheit, J. Faupel, E. Süske, T. Scharf, C. Fuhse, M. Störmer, K. Sturm, M. Seibt, H. Kijewski, 
D. Nelke, E. Panchenko and M. Buback, Advances in Solid State Physics, Springer Berlin Heidelberg, Berlin, Heidelberg, 2003, pp. 505-518.

54 T. Gao, H. FjellvÅg and P. Norby, Anal. Chim. Acta, 2009, 648, 235-239.

55 X. Gu, J. Yue, L. Li, H. Xue, J. Yang and X. Zhao, Electrochim. Acta, 2015, 184, 250-256.

56 R. Tholkappiyan, A. N. Naveen, K. Vishista and F. Hamed, J. Taibah Univ. Sci., 2018, 12, 669-677.

57 S. Ardizzone, G. Fregonara and S. Trasatti, Electrochim. Acta, 1990, 35, 263-267.

58 Y.-H. Lee, K.-H. Chang and C.-C. Hu, J. Power Sources, 2013, 227, 300-308.

59 J. Duay, S. A. Sherrill, Z. Gui, E. Gillette and S. B. Lee, $A C S$ Nano, 2013, 7, 1200-1214.

60 J. Wang, J. Polleux, J. Lim and B. Dunn, J. Phys. Chem. C, 2007, 111, 14925-14931.

61 C. Liu, E. I. Gillette, X. Chen, A. J. Pearse, A. C. Kozen, M. A. Schroeder, K. E. Gregorczyk, S. B. Lee and G. W. Rubloff, Nat. Nanotechnol., 2014, 9, 1031-1039.

62 C. Sun, Y. Zhang, S. Song and D. Xue, J. Appl. Crystallogr., 2013, 46, 1128-1135.

63 H. Li, X. Zhang, R. Ding, L. Qi and H. Wang, Electrochim. Acta, 2013, 108, 497-505.

64 Y. Xu, Y. Tao, X. Zheng, H. Ma, J. Luo, F. Kang and Q.-H. Yang, Adv. Mater., 2015, 27, 8082-8087.

65 M. Ghidiu, M. R. Lukatskaya, M.-Q. Zhao, Y. Gogotsi and M. W. Barsoum, Nature, 2014, 516, 78-81.

66 M. Acerce, D. Voiry and M. Chhowalla, Nat. Nanotechnol., 2015, 10, 313-318.
67 J. Yan, Q. Wang, T. Wei, L. Jiang, M. Zhang, X. Jing and Z. Fan, ACS Nano, 2014, 8, 4720-4729.

68 J. Yan, Q. Wang, T. Wei and Z. Fan, Adv. Energy Mater., 2014, 4, 1300816.

69 C. Yang, L. Zhang, N. Hu, Z. Yang, Y. Su, S. Xu, M. Li, L. Yao, M. Hong and Y. Zhang, Chem. Eng. J., 2017, 309, 89-97.

70 X. Zhao, L. Zhang, S. Murali, M. D. Stoller, Q. Zhang, Y. Zhu and R. S. Ruoff, ACS Nano, 2012, 6, 5404-5412.

71 J. Pedrós, A. Boscá, J. Martínez, S. Ruiz-Gómez, L. Pérez, V. Barranco and F. Calle, J. Power Sources, 2016, 317, 35-42.

72 J. Yan, Q. Wang, C. Lin, T. Wei and Z. Fan, Adv. Energy Mater., 2014, 4, 1400500.

73 L. Yan, D. Li, T. Yan, G. Chen, L. Shi, Z. An and D. Zhang, ACS Sustainable Chem. Eng., 2018, 6, 5265-5272.

74 A. Teli, S. Bekanalkar, D. Patil, S. Pawar, T. Dongale, J. Shin, H. Kim and P. Patil, J. Electroanal. Chem., 2020, 856, 113483.

75 A. M. Teli, S. A. Beknalkar, D. S. Patil, S. A. Pawar, D. P. Dubal, V. Y. Burute, T. D. Dongale, J. C. Shin and P. S. Patil, Appl. Surf. Sci., 2020, 511, 145466.

76 V. Mane, D. Malavekar, S. Ubale, R. Bulakhe, I. In and C. Lokhande, Electrochim. Acta, 2020, 335, 135613.

77 Y. Tian, C. Yang, W. Que, X. Liu, X. Yin and L. B. Kong, J. Power Sources, 2017, 359, 332-339.

78 Y.-H. Lin, T.-Y. Wei, H.-C. Chien and S.-Y. Lu, Adv. Energy Mater., 2011, 1, 901-907.

79 Y. Wu, S. Liu, H. Wang, X. Wang, X. Zhang and G. Jin, Electrochim. Acta, 2013, 90, 210-218.

80 E. A. Ponzio, T. M. Benedetti and R. M. Torresi, Electrochim. Acta, 2007, 52, 4419-4427. 